\title{
Effect of Sn addition on the microstructural characteristics and mechanical properties of the titanium alloy (Ti6Al4V)
}

\author{
M. Rajadurai ${ }^{1}$, A. Raja Annamalai ${ }^{2 *}$ \\ ${ }^{1}$ School of Mechanical Engineering, VIT, Vellore 632014, India \\ ${ }^{2}$ Centre for Innovative Manufacturing Research, VIT, Vellore 632014, India
}

Received 27 June 2017, received in revised form 11 May 2018, accepted 4 June 2018

\begin{abstract}
Ti-6Al-4V-x $\operatorname{Sn}(x=2,4$, and 6 wt. $\%)$ alloys were developed for the aerospace application through the near net shaped technique powder metallurgy route. Spark Plasma Sintering (SPS) was used to sinter the samples. The influence of Sn particles on the microstructural characteristics and mechanical properties of titanium alloy was examined through a novel technique called SPS. It has been found that Sn has a strong solid solution strengthening ability in the titanium alloy (Ti6Al4V). Moreover, the addition influences the microstructure and mechanical properties of titanium alloy. With increasing the percentage of Sn content, the density of the samples decreases, and the mechanical properties like yield stress (YS), ultimate tensile stress (UTS), the percentage of elongation and the hardness are greatly varying. From this investigation, it is found that YS, UTS, the percentage of elongation of the samples of Ti6Al4V-2Sn alloy exhibit better values than of Ti6Al4V-4Sn and Ti6Al4V-6Sn alloys, and the hardness of the samples is increasing with the addition of Sn from 2 to $6 \%$.
\end{abstract}

K e y w o r d s: Ti-6Al-4V-xSn $(x=2,4$, and 6 wt.\%), Spark Plasma Sintering (SPS), microstructure, mechanical properties

\section{Introduction}

The demand for the usage of lightweight and high strength materials in the aircraft industries is increasing to improve the performance of an aircraft. The commercial pure titanium material does not reach the increased demand of the rapid industrial growth $[1$, $2]$. In order to strengthen the titanium alloy, different alloying elements like Sn, Zr (neutral stabilizer), $\mathrm{Al}, \mathrm{O}, \mathrm{N}, \mathrm{C}$ ( $\alpha$ stabilizer $), \mathrm{Mo}, \mathrm{V}, \mathrm{Ta}, \mathrm{Nb}$ ( $\beta$ isomorphous stabilizer) and $\mathrm{Fe}, \mathrm{Mn}, \mathrm{Cr}, \mathrm{Co}, \mathrm{Ni}, \mathrm{Cu}, \mathrm{Si}, \mathrm{H}$, ( $\beta$ eutectoid stabilizer) are added $[2,3]$. The material having high strength-to-weight ratio, high stiffness, good corrosion resistance [4-8], good weldability, and high resistance to temperature is $\mathrm{Ti} 6 \mathrm{Al} 4 \mathrm{~V}$ alloy [9-19], which was developed by adding $6 \%$ aluminium ( $\alpha$ stabilizer), $4 \%$ vanadium ( $\beta$ stabilizer), and remaining titanium in the year $1954[20,21]$. Nowadays, titanium alloys (Ti6Al4V - two-phase $\alpha, \beta$ alloys) are greatly used in different industries: aircraft, spacecraft, marine, automotive, biomedical, chemical, etc.
$[22,23]$. Even though, by the addition of $\alpha$ stabilizer elements only concentrating on corrosion resistance, $\beta$ eutectoid elements can bring the brittle compound phase, and the $\beta$ isomorphous elements form the intergranular $\beta$ phase that limits the ductility, strengthening effect, and the high-temperature performance. Limited strengthening effects and high cost restricted the large-scale production in the field of applications [24-26]. The previous researchers demonstrated that a neutral alloying element like Sn has a large solubility so that the mechanical properties are greatly improved [24-26]. Hsu et al. [24] investigated that elasticity, bending modulus, and bending strength of the casting (Ti-Sn alloy) were higher than for commercial pure titanium alloy. Nouri et al. [27] examined the Widmanstätten structure that was formed in the twophase $\mathrm{Ti}$ alloy (Ti-Nb-Sn) with the combination of interlaced secondary $\alpha$ and $\beta$. Most of the researchers focused on casting Ti-Sn alloy and Ti-Sn- $x$ ternary two-phase titanium alloy. The oxidation formation, grains coarsening, and the impurities were the general

*Corresponding author: e-mail address: raja.anna@gmail.com 
Table 1. Elemental composition of pre-alloyed Ti-6Al-4V powder (wt.\%)

\begin{tabular}{cccccccccc}
\hline Elements & $\mathrm{Ti}$ & $\mathrm{Al}$ & $\mathrm{V}$ & $\mathrm{C}$ & $\mathrm{O}$ & $\mathrm{N}$ & $\mathrm{H}$ & $\mathrm{Fe}$ & Others \\
\hline & 88.65 & 6.40 & 4.20 & 0.01 & 0.13 & 0.01 & 0.001 & 0.21 & 0.39 \\
\hline
\end{tabular}

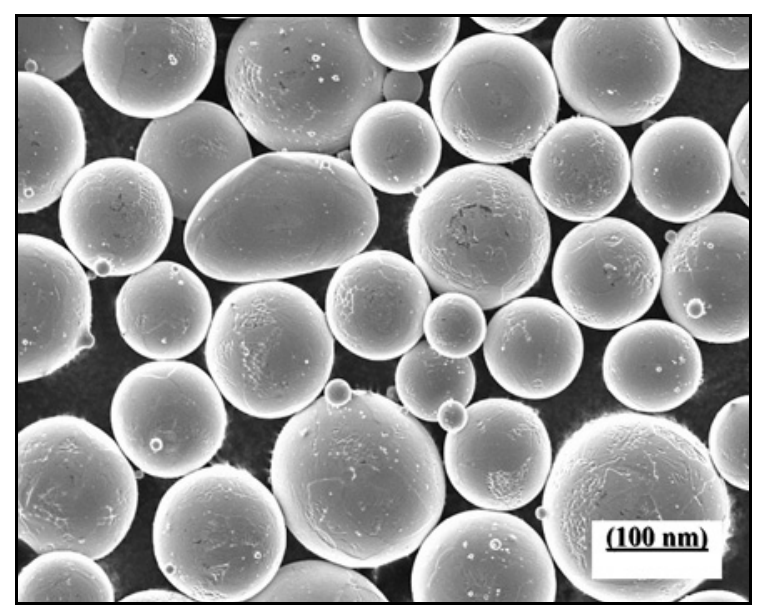

Fig. 1. SEM images of Ti-6Al-4V powder.

problems in the casting of titanium alloy [27]. High-temperature cooling coarsened lath-like Widmanstätten microstructure was easily formed which deteriorated fatigue strength and ductility greatly [28, 29]. Niinomi et al. [29] studied the influence of addition of $\mathrm{Sn}$ in the microstructural characteristics and mechanical properties of the Ti-Sn binary alloy. The neutral alloying element Sn plays an effective role in the substitution of solid solution, which has been already confirmed in the classical physical metallurgy. Moreover, large attention taken in the Ti-Sn alloy focused on the application of strengthening element [30]. It has been investigated the fabrication of $\mathrm{Ti}-\mathrm{Sn}$ alloy has never been achieved with high strength and ductility over the past few decades. Moreover, the effect of addition of $\mathrm{Sn}$ in the microstructure and mechanical properties of Ti-Sn binary alloy has not been clear for the long time [31]. Comparing the traditional titanium casting and wrought production processes, powder metallurgy (PM) methods like conventional pressing and sintering [32, 33], and additive manufacturing methods have major advantages like fine microstructure of the components, avoiding casting defects, better diffusion process and cost reduction from near net shaping capabilities [34]. In the recent development of PM titanium industry, The Boeing Company (Seattle, WA, USA) approved the near net shaped Ti6Al4V alloy products for the commercial aircrafts [34]. The standardized quality management system AS9100/ISO9001 certification has received the PM titanium metal products in April 2013 [35]. Besides, in powder metallurgy (PM) sintering by conventional methods is difficult because of the extreme
Table 2. Elemental composition of titanium alloy samples

\begin{tabular}{lc}
\hline Alloy 1 & Ti-6Al-4V \\
Alloy 2 & Ti-6Al-4V-2Sn \\
Alloy 3 & Ti-6Al-4V-4Sn \\
Alloy 4 & Ti-6Al-4V-6Sn \\
\hline
\end{tabular}

chemical reaction with atmospheric gases like nitrogen, hydrogen and oxygen, especially at elevated temperatures [21, 36, 37]. So, the most popular sintering methods in PM are field assisted sintering techniques like SPS [38-40].

We thought that adding the small content of Sn in pre-alloyed Ti-6Al-4V was changing its mechanical properties as well as enhancing the strengthening ability. The present work is mainly focused on the effect of the addition of Sn on the microstructural characteristics and the mechanical properties of the pre-alloyed Ti6Al4V material. The primary aim of this work is to develop a new titanium alloy for aerospace application with high mechanical performance.

\section{Materials and methods}

\subsection{Powder morphology}

The SEM (Scanning Electron Microscope) was used to investigate the powder morphology of prealloyed Ti-6Al-4V powders (Advanced Powders and Coatings, Canada) and Sn powders (Krish Met Tech Pvt. Ltd, Chennai), which are composed of uniformly distributed spherical particles of the size within the range of $45-106 \mu \mathrm{m}$ as shown in Fig. 1. The nominal chemical composition of the received powders is represented in Table 1.

\subsection{Alloy preparations}

In this study, four different compositions of titanium alloys Ti-6Al-4V and Ti-6Al-4V- $x$ Sn $(x=2,4$, and 6 wt.\%) were prepared from the commercial pre alloyed Ti-6Al-4V powders (Advanced Powders and Coatings, Canada) and Sn powders (Krish Met Tech Pvt. Ltd, Chennai), which are given in Table 2.

\subsection{Sintering}

The premixed powders of four different composi- 
Ta b le 3. Percentage of the sintered density of titanium alloy samples

\begin{tabular}{ccc}
\hline Sr. No. & Alloy & \% of the sintered density \\
\hline 1 & Ti-6Al-4V & 96.2 \\
2 & Ti-6Al-4V-2Sn & 93.5 \\
3 & Ti-6Al-4V-4Sn & 88.6 \\
4 & Ti-6Al-4V-6Sn & 86.8 \\
\hline
\end{tabular}

tions were poured into a high-density graphite die, and the graphite punch was properly plugged at both ends, then the die assembly was properly placed into the SPS unit. The specimens were sintered at the temperature of $900^{\circ} \mathrm{C}$ for 2 min under $50 \mathrm{MPa}$ compacting pressure, $100^{\circ} \mathrm{C} \mathrm{min}^{-1}$ heating rate and $<10^{-3}$ torr vacuum. Generally, the titanium materials are readily picked up interstitial elements such as oxygen, hydrogen, and nitrogen; the materials were handled with the high vacuum furnace. An optical pyrometer used to monitor and measure the temperature of the graphite die. Finally, the disk-shaped sintered samples with $30 \mathrm{~mm}$ diameter and 7 to $8 \mathrm{~mm}$ height (from $30 \mathrm{~g}$ of mixed compositions) were furnace-cooled to room temperature. The cylindrical samples were machined by electro-discharge machining for material characterization and mechanical testing.

\subsection{Characterization}

All the machined specimens were properly mounted on the mount (Transparent Epoxy Resin) for grinding, polishing by the grit papers $(120,220,400$, 600 , and 1000) and the diamond paste $(3-4 \mu \mathrm{m}$ and 0.5-1 $\mu \mathrm{m})$. Etching was done based on ASTM E407 using Kroll's etchant comprising $3 \mathrm{ml} \mathrm{HF}, 6 \mathrm{ml} \mathrm{HNO}$ and $100 \mathrm{ml} \mathrm{H}_{2} \mathrm{O}$. The microstructural characteristics and elemental proportions of the samples were investigated by SEM equipped with EDS (Energy Dispersive Spectrometry). The polished sample was used to obtain the scanning electron micrographs by SEM in Secondary Electron (SE) modes and the chemical composition of the samples by EDS (Zeiss Evo 50, Carl Zeiss SMT Ltd., UK). The microstructure of the specimen was obtained by an optical microscope (LEICA DM2500, Germany) which has the capability of obtaining the digital image. Fractured surface was cleaned with acetone and then viewed under SEM for fractography analysis.

\subsection{Mechanical testing}

The density of the specimens was obtained by the Archimedes' principle method. The mechanical properties (Young's modulus, ultimate tensile stress, \% of elongation) of the micro-tensile samples were measured by using the universal testing machine (INSTRON) with $0.2 \mathrm{~mm} \mathrm{~s}^{-1}$ initial strain rate $\left(0.2 \mathrm{~mm} \mathrm{~min}^{-1}\right.$ crosshead speed) of full-load $10 \mathrm{kN}$. To ensure reproducibility, mechanical testing of five samples was carried out at room temperature. The microhardness of the sintered compacts was measured with standard diamond indenter with an angle of $136^{\circ}$ (ECONOMET-VH-1MD, Chennai Metco pvt. Ltd.), and the indentation was done to yield the results in HRC scale. The microhardness testing was carried out from the polished area in the specimen, and the values were reported from 30 indentations (Mean, Standard Deviation) in the form of $6 \times 5$ matrices of indents with a space length of $10 \mu \mathrm{m}$ between the indents. The fracture topologies of the samples were examined by SEM.

\section{Results and discussion}

\subsection{Densification}

The sintering densification of the specimen was affected by powder particle size, compaction pressure, isothermal holding time and sintering temperature [45]. The densities of the four sintered specimens were examined by the principle Archimedes' method, and the values are listed in Table 3 . The results show that the sintered densities are decreasing with an increase of the amount of additions of $\mathrm{Sn}$ in the titanium alloy, they range from 96.255 to $86.840 \%$. The addition of 2, 4 and 6 wt. $\%$ of Sn particles advanced a decline in the densification of the samples which is shown in Table 3. Due to the different size the particles with the incomplete dissolution of the elements in the alloy exhibit less densification. It is evident that the presence of tin particles influences the densification response of the Ti6Al4V alloy at $900^{\circ} \mathrm{C}$.

\subsection{Microstructural characteristics}

Optical microscope, SEM with EDAX were used to study the microstructural characteristics and elemental composition of four sintered samples. The optical microscope image in Fig. 2 depicts the microstructure of four different compositions of Ti-6Al-4V and Ti$6 \mathrm{Al}-4 \mathrm{~V}-x \mathrm{Sn}$ alloy $(x=2,4$, and 6 wt. $\%)$ with the Widmanstätten-like microstructure from the combination of two phases $(\alpha+\beta)$ with the variation of porosity levels. The microstructural characteristics of 

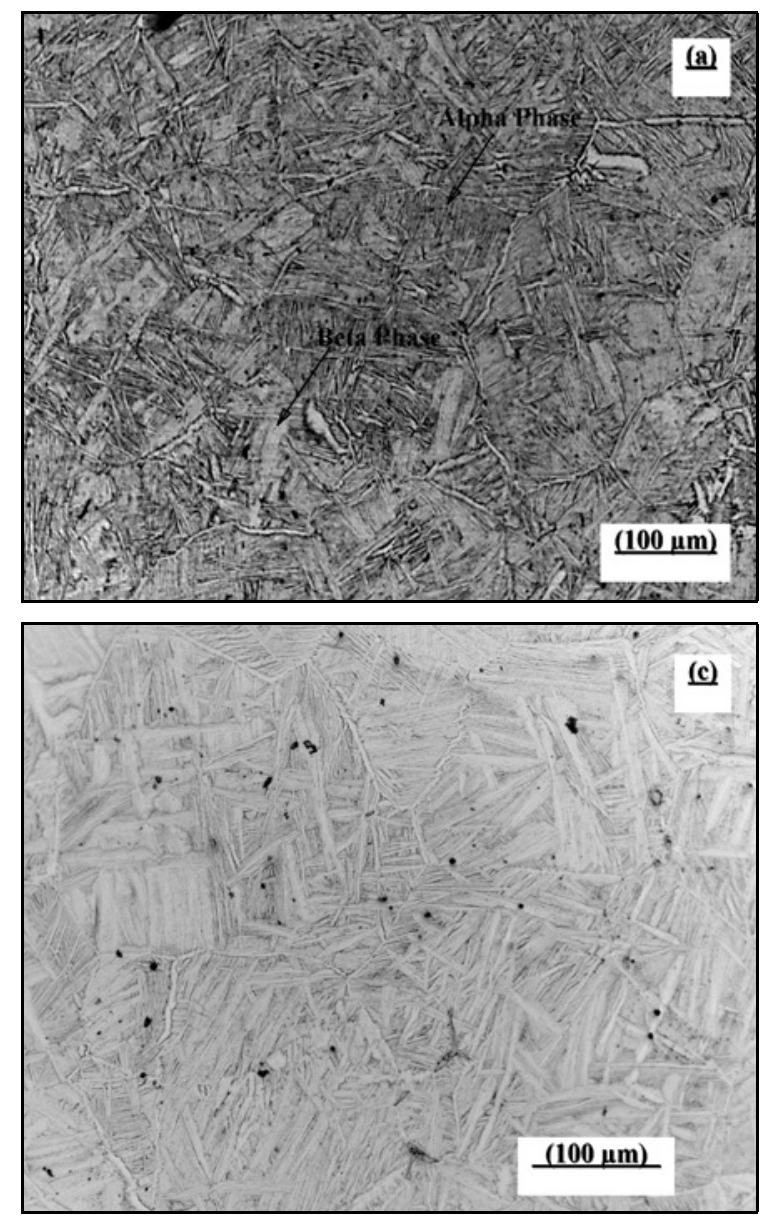
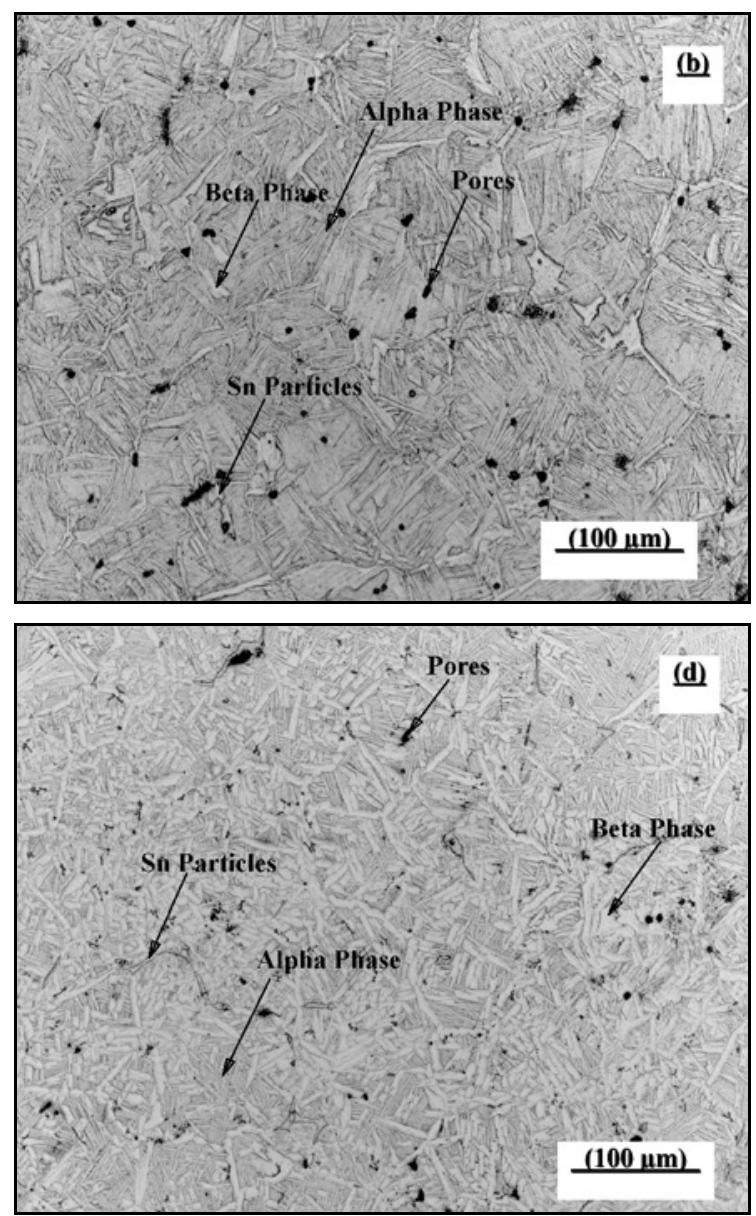

Fig. 2. Optical microstructures of the titanium alloy: (a) Ti-6Al-4V, (b) Ti-6Al-4V-2Sn, (c) Ti-6Al-4V-4Sn, and (d) Ti-6Al-4V-6Sn.

the sample Ti6Al4V alloy in Fig. 2 depicts the small lamella sizes of Widmanstätten microstructures distributed throughout the specimen were developed. In Figs. 2b,c it is depicted that the microstructure of the samples Ti-6Al-4V-2Sn alloy and Ti-6Al-4V-4Sn alloy, which consists of a basket weave like (Widmanstätten) microstructure, distributed throughout the samples. The dark colour represents the $\alpha$-phase plates and $\beta$-phase present among the $\alpha$-phase plates, which is shown in white colour. Moreover, furnace cooling of the samples tends to produce the coarse Widmanstätten microstructure which is characterized by colonies of $\alpha$ platelets situated at crystallographic variations. In this microstructure, the black colour indicates the amount of porosity present in the samples. Similarly Fig. 2d depicts the micrographs of the samples Ti6Al4V-6Sn alloy which consists of the equiaxed particles of primary $\alpha$-phase and $\beta$-phase along the grain boundaries with the large amount of porosity. The $\alpha$ platelets size is increased because the titanium alloy compositions became comparably higher in $\alpha$ stabilizing agent $\mathrm{Sn}$ from 2 to $6 \%$ of the total volume in the alloy (Ti-6Al-4V). Due to this increasing effect of $\alpha$ platelet size, the $\beta$-phase growth kinetics decreases with increasing $\alpha$ stabilizer content Sn. From
Fig. 2 note that the lamellar structure is as yet the prevalent microstructure morphology in Ti6Al4V-2Sn alloy. Conversely, the samples with 4 and $6 \%$ weight of Sn expansion show the micrographs with no defined $\alpha$ colony; at the end lamellar microstructure is completely stifled. So, the microstructure of Ti6Al4V samples shows lower $\beta$-phase region in Fig. 2. An increase of the addition of $\mathrm{Sn}$ in the titanium alloy changes the size of the lamellae with high porosity and tends to reduce the mechanical properties.

The SEM and EDAX analysis of four sintered samples Ti-6Al-4V and Ti-6Al-4V- $x$ Sn alloy $(x=2,4$, and 6 wt.\%) confirms their microstructure with $\alpha$ - and $\beta$-phases, grain boundaries, grain properties and the elemental compositions accurately. Figure 3 shows SEM images of four samples with the distribution of the $\alpha$ - and $\beta$-phases and pores. The EDAX results show only the presence of titanium, aluminium, vanadium, and tin elements in the sample with their weight and atomic percentages, which is illustrated in Fig. 4.

\subsection{Mechanical properties}

The tensile testing was carried out using UTM and the mechanical properties YS, UTS and percentage of 

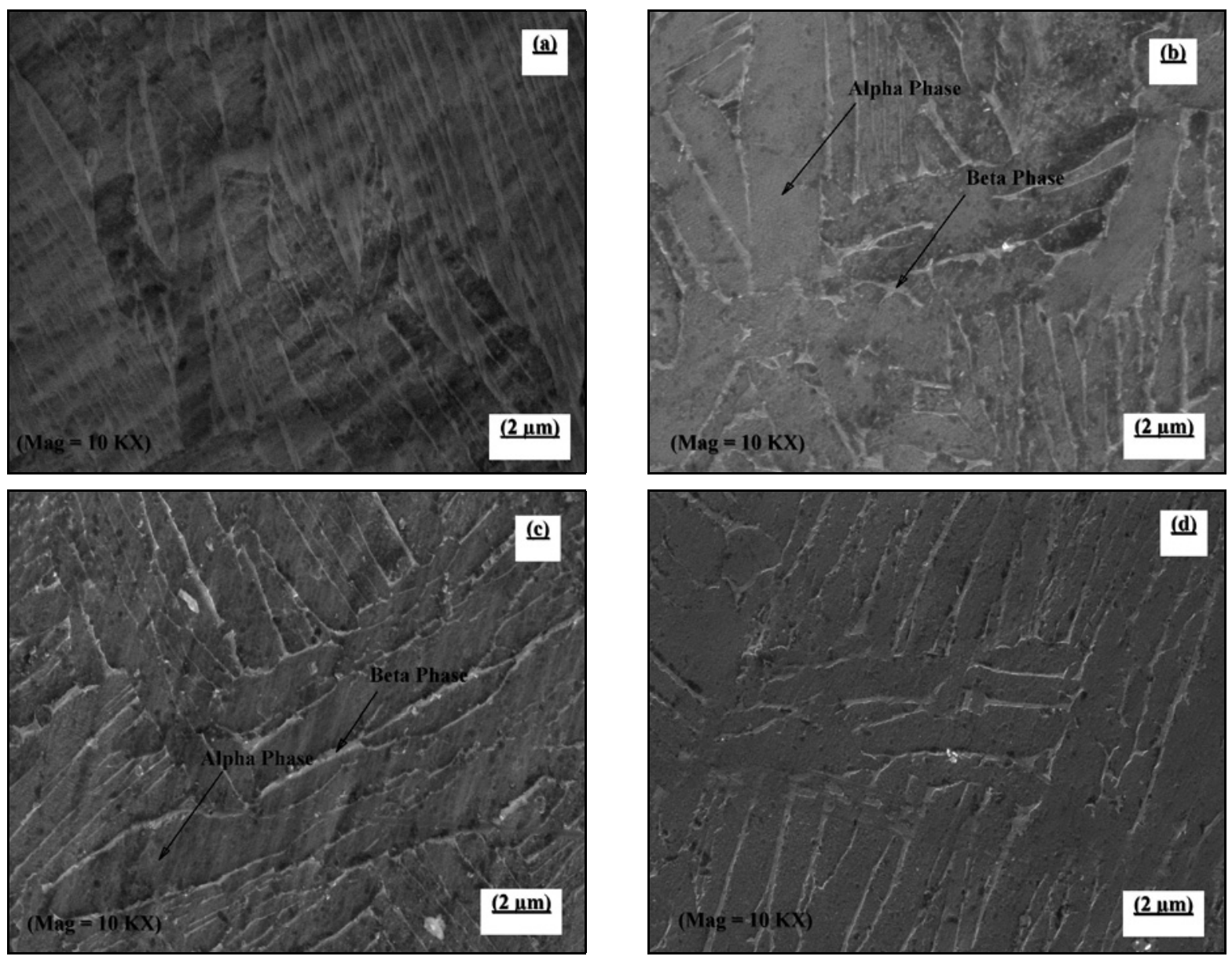

Fig. 3. SEM images of the titanium alloy: (a) Ti-6Al-4V, (b) Ti-6Al-4V-2Sn, (c) Ti-6Al-4V-4Sn, and (d) Ti-6Al-4V-6Sn.

Ta ble 4. Tensile testing results of titanium alloy samples

\begin{tabular}{ccccc}
\hline Sr. No. & Alloy & YS (MPa) & UTS (MPa) & \% Elongation \\
\hline 1 & Ti-6Al-4V & 1523 & 1691 & 16.10 \\
2 & Ti-6Al-4V-2Sn & 1412 & 1502 & 15.29 \\
3 & Ti-6Al-4V-4Sn & 1393 & 1464 & 4.30 \\
4 & Ti-6Al-4V-6Sn & 1335 & 1364 & 1.03 \\
\hline
\end{tabular}

elongation of the four samples Ti-6Al-4V and Ti-6Al$-4 \mathrm{~V}-x$ Sn alloy $(x=2,4$, and $6 \mathrm{wt} . \%)$ are presented in Table 4. It can be observed that without the addition of Sn, Ti-6Al-4V alloy exhibited high mechanical values of UTS, which is $1691 \mathrm{MPa}$. As the content of tin in the titanium alloy increased from 2 to $6 \%$ the mechanical properties of the samples are sharply declined. A critical reduction of mechanical properties (YS and UTS) is seen from the titanium alloy Ti-6Al-4V with Sn. Then again, the percentage of elongation declines roughly by $14 \%$. These results reflect the changing pattern of the microstructure of the samples because of the addition of $\mathrm{Sn}$ in the titanium alloy. As mentioned above, the microstructure of the sample without the addition of tin contains $\alpha$-phase and $\beta$-phase uniformly distributed throughout the specimen with high densification. The addition of Sn particles from 2 to $6 \%$, the lamellar structure was suppressed by a large number of pores. The decrease of tensile properties is identified near the pores. During the tensile test, the nearness of pores diminishes the powerful load carrying cross-segment zone and goes about the stress concentration site for strain confinement and harm, decreasing the mechanical properties like strength and percentage of elongation [41]. In actuality, the sum and distribution of porosity are essential parameters with a specific end goal to depict the mechanical properties of sintered materials [42].

Polished titanium alloy samples were tested for Rockwell's hardness, which was measured in HRC 


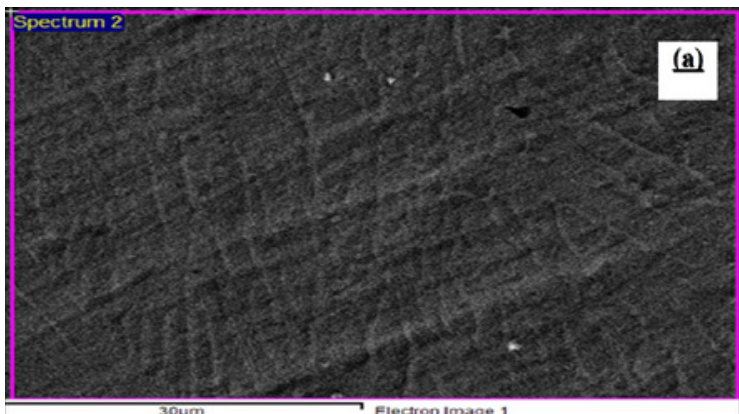

\begin{tabular}{|c|c|c|c|}
\hline 30 & & fon Image 1 & \\
\hline Composition & Element & Weight $\%$ & Atomic\% \\
\hline \multirow{4}{*}{ Ti-6A1-4V } & Ti K & 90.06 & 86.41 \\
\hline & A1 K & 5.77 & 9.83 \\
\hline & V K & 4.17 & 3.76 \\
\hline & Totals & 100.00 & \\
\hline
\end{tabular}
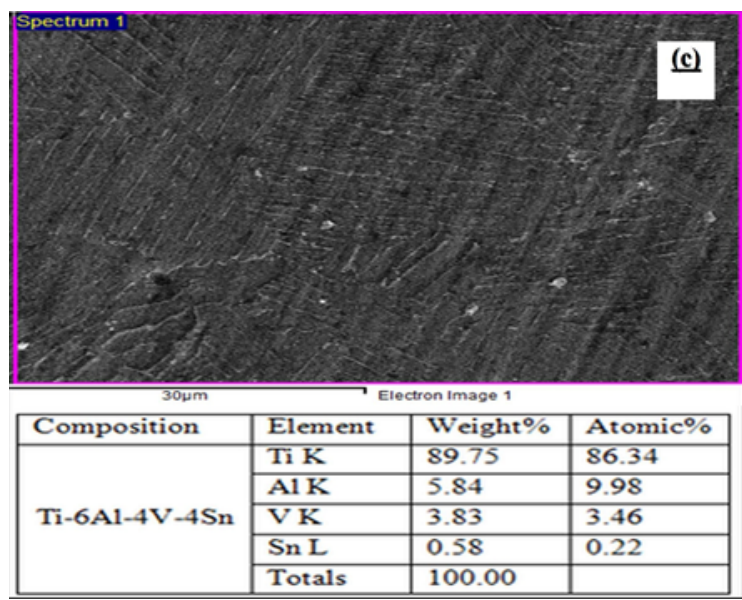

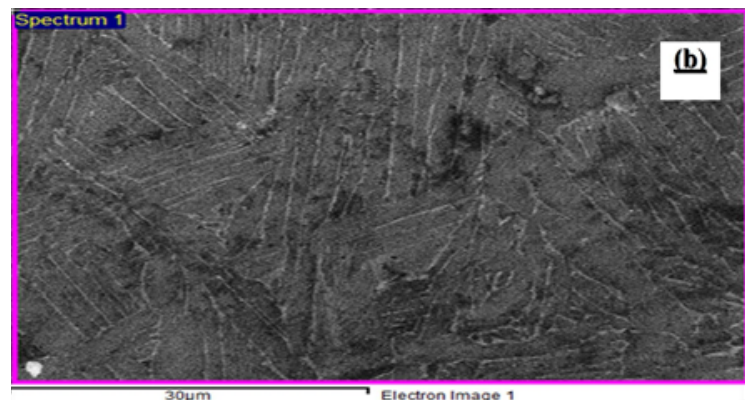

\begin{tabular}{|l|l|l|l|}
\hline Composition & Element & Weight\% & Atomic\% \\
\hline \multirow{4}{*}{ Ti-6A1-4V-2Sn } & Ti K & 89.47 & 86.06 \\
\cline { 2 - 4 } & A1 K & 6.14 & 10.49 \\
\cline { 2 - 4 } & V K & 3.37 & 3.05 \\
\cline { 2 - 4 } & Sn L & 1.01 & 0.39 \\
\cline { 2 - 4 } & Totals & 100.00 & \\
\hline
\end{tabular}

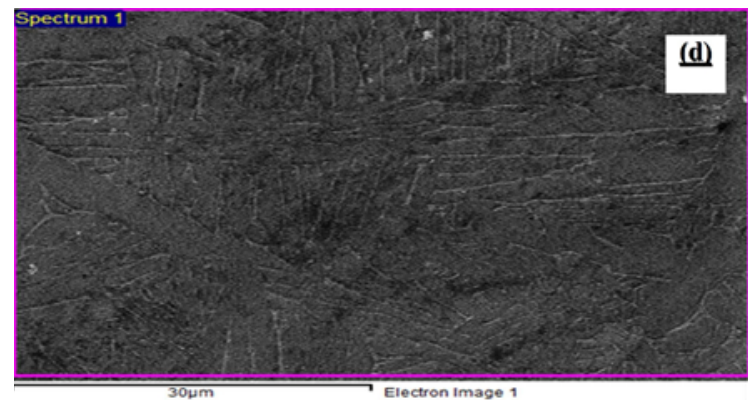

\begin{tabular}{|c|c|c|c|}
\hline 30um & & ron Image 1 & \\
\hline Composition & Element & Weight \% & Atomic\% \\
\hline \multirow{5}{*}{ Ti-6A1-4V $-6 \mathrm{Sn}$} & Ti K & 89.71 & 85.98 \\
\hline & A1 K & 6.24 & 10.62 \\
\hline & VK & 3.58 & 3.23 \\
\hline & Sn L & 0.47 & 0.18 \\
\hline & Totals & 100.00 & \\
\hline
\end{tabular}

Fig. 4. EDAX analysis of the titanium alloy: (a) Ti-6Al-4V, (b) Ti-6Al-4V-2Sn, (c) Ti-6Al-4V-4Sn, and (d) Ti-6Al-4V-6Sn.

Ta b le 5. Hardness values of titanium alloy sample

\begin{tabular}{ccc}
\hline Sr. No. & Alloy & Avg. hardness value (HRC) \\
\hline 1 & Ti-6Al-4V & 33.2 \\
2 & Ti-6Al-4V-2Sn & 23.8 \\
3 & Ti-6Al-4V-4Sn & 25.9 \\
4 & Ti-6Al-4V-6Sn & 26.9 \\
\hline
\end{tabular}

scale and the results are listed in Table 5. From the four samples, Ti-6Al-4V alloy has a higher hardness (33.2 HRC) than the remaining three. The hardness of the samples decreased due to the addition of $2 \%$ $\mathrm{Sn}$ in the titanium alloy. Results show that the titanium alloy with $2 \%$ Sn has the lowest hardness but the hardness increases as the increase of Sn in the titanium alloy tends to suppress the lamellar microstructure, which infers the addition of Sn particles has a strong solid-solution hardening impact [43].

Figure 5 shows SEM fractography of the samples Ti-6Al-4V and Ti-6Al-4V- $x$ Sn alloy $(x=2,4$, and 6 wt.\%). The dimples are uniformly distributed in the fractured area of titanium alloy samples, which is an evidence that the ductile mode of fracture took place in the fractured area. Moreover, the dimple's depth, shape, and size are decreasing with increasing the content of Sn particles; it can be observed that the result is coincident with the percentage of elongation (decreased $14 \%$ ) of the samples with Sn particles.

\section{Conclusions}

From this investigation, the mechanical testing and material characterization of titanium alloy brings the following conclusions:

Addition of Sn particles impacts the microstructural characteristics and mechanical properties of the titanium alloy (Ti6Al4V). 

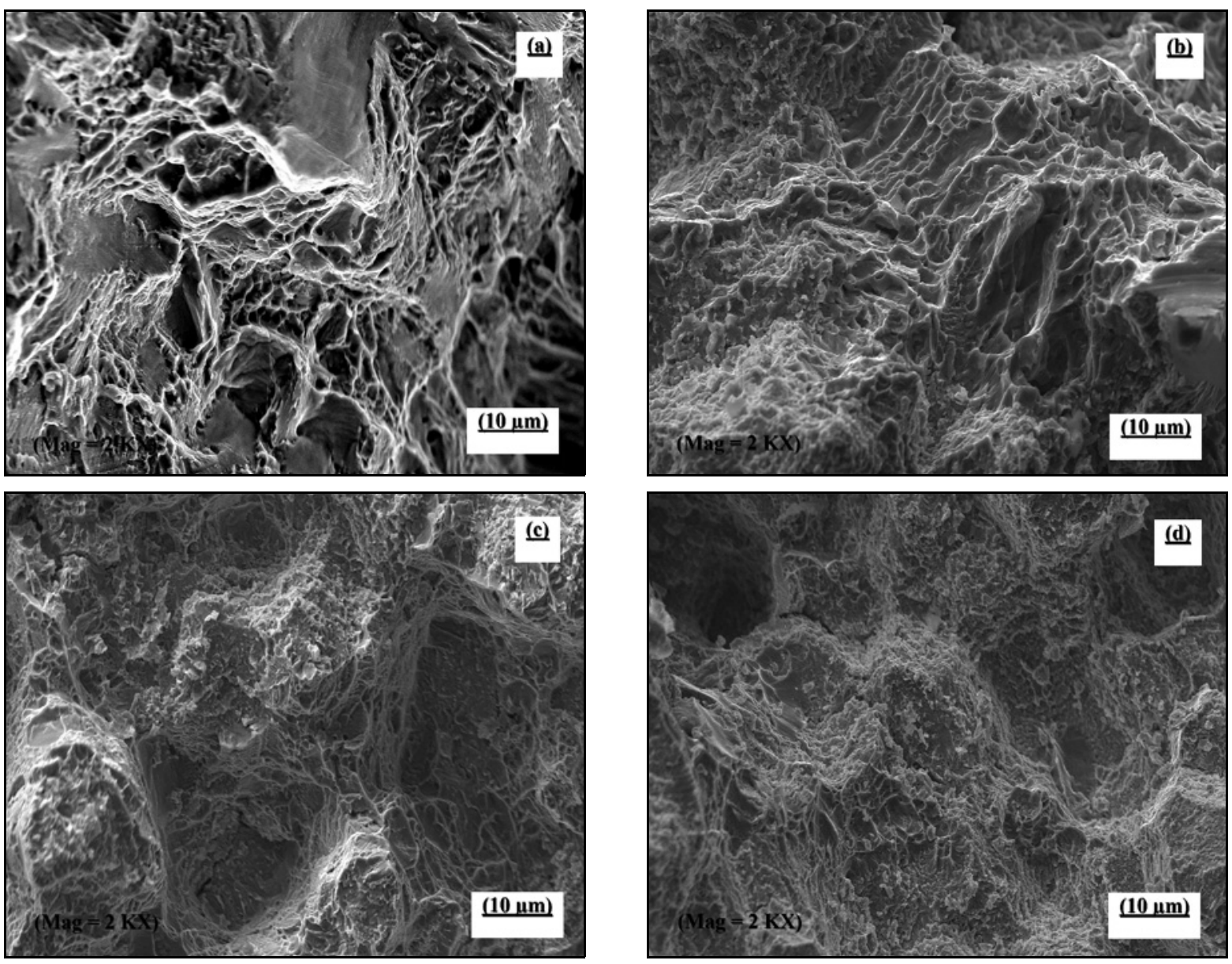

Fig. 5. Fractography images of the titanium alloy: (a) Ti-6Al-4V, (b) Ti-6Al-4V-2Sn, (c) Ti-6Al-4V-4Sn, and (d) Ti-6Al$4 \mathrm{~V}-6 \mathrm{Sn}$.

Increasing the amount of $\mathrm{Sn}$ in the titanium alloy changes the microstructural characteristic which reveals increasing the pores in the samples, due to that the sintered density reduced from 96.26 to $86.84 \%$.

The YS (1412 MPa), UTS (1502 MPa) and the percentage of elongation (15.29) with $2 \%$ addition of Sn sample exhibit higher values than the 4 and $6 \%$ addition of $\mathrm{Sn}$ in the titanium alloy.

The hardness of the samples slightly increased, from $23.8 \mathrm{HRC}$ to $26.9 \mathrm{HRC}$, with the addition of Sn in the titanium alloy.

\section{References}

[1] Yu, Q., Qi, L., Tsuru, T., Traylor, R., Rugg, D., Morris, J. W., Asta, M., Chrzan, D. C., Minor, A. M.: Science, 347, 2015, p. 635. doi:10.1126/science.1260485

[2] Banerjee, D., Williams, J. C.: Acta Metall., 61, 2013, p. 844. doi:10.1016/j.actamat.2012.10.043

[3] Long, M., Rack, H. J.: Biomaterials, 19, 1998, p. 1621. doi:10.1016/S0142-9612(97)00146-4

[4] Madeira, S., Pinto, A. M. P., Rodrigues, L. C., Carvalho, O., Miranda, G., Reis, R. L., Joăo Caramęs,
Silva, F. S.: Mater. Design, 120, 2017, p. 394. doi:10.1016/j.matdes.2017.02.038

[5] Lin, K.-L., Lin, C.-C.: J. Am. Ceram. Soc., 88, 2005, p. 1268. doi:10.1111/j.1551-2916.2005.00218.x

[6] Polmear, I. J.: Light Alloys: From Traditional Alloys to Nanocrystals. Oxford, Butterworth-Heinemann 2005.

[7] Rack, H. J., Qazi, J. I.: Mat. Sci. Eng. C, 26, 2006, p. 1269. doi:10.1016/j.msec.2005.08.032

[8] Bolzoni, L., Ruiz-Navas, E. M., Neubauer, E., Gordo, E.: Mater. Chem. Phys., 131, 2012, p. 672. doi:10.1016/i.matchemphys.2011.10.034

[9] Wojtaszek, M. Sleboda, T.: J Alloy Compd., 615, 2014, p. 546. doi:10.1016/j.jallcom.2014.01.161

[10] Doni, Z., Alves, A. C., Toptan, F., Gomes, J. R., Ramalho, A., Buciumeanu, M., Palaghian, L., Silva, F. S.: Mater. Design, 52, 2013, p. 47. doi:10.1016/i.matdes.2013.05.032

[11] Yu, C., Cao, P., Jones, M. I.: Metals, 7, 2017, p. 67. doi: $10.3390 / \operatorname{met} 7020067$

[12] Donachie, J. M. J.: Titanium - A Technical Guide. Materials Park, ASM International 2000.

[13] Froes, F. H.: Titanium - Physical Metallurgy, Processing and Applications. Materials Park, ASM International 2015. 
[14] Bolzoni, L., Montealegre Meléndez, I., Ruiz-Navas, E. M., Gordo, E.: Mat. Sci. Eng. A, 546, 2012, p. 189. doi:10.1016/j.msea.2012.03.050

[15] Attar, H. Calin, M., Zhang, L. C., Scudino, S., Eckert, J.: Mat Sci Eng A-Struct., 593, 2014, p. 170. doi:10.1016/j.msea.2013.11.038

[16] Attar, H., Bonisch, M., Calin, M., Zhang, L. C., Scudino, S., Eckert, J.: Acta Mater., 76, 2014, p. 13. doi:10.1016/j.actamat.2014.05.022

[17] Ehtemam-Haghighi, S., Prashanth, K. G., Attar, H., Chaubey, A. K., Cao, G. H., Zhang, L. C.: Mater Design, 111, 2016, p. 592. doi:10.1016/j.matdes.2016.09.029

[18] Ehtemam-Haghighi, S., Cao, G. H., Zhang, L. C.: J Alloy Compd., 692, 2017, p. 892. doi:10.1016/j.jallcom.2016.09.123

[19] Okulov, I. V., Volegov, A. S., Attar, H., Bonisch, M. Ehternam-Haghighi, S., Calin, M., Eckert, J.: J. Mech. Behav. Biomed., 65, 2017, p. 866. doi:10.1016/j.jmbbm.2016.10.013

[20] Garbiec, D., Siwak, P., Mróz, A.: Arch. Civ. Mech. Eng., 16, 2016, p. 702. doi:10.1016/i.acme.2016.04.009

[21] Quan, Y., Zhang, F., Rebl, H., Nebe, B., Kessler, O., Burkel, E.: Mat. Sci. Eng. A, 565, 2013, p. 118. doi:10.1016/j.msea.2012.12.026

[22] Tabrizi, S. G., Sajjadi, S. A., Babakhani, A., Lu, W. Mat. Sci. Eng. A, 624, 2015, p. 271. doi:10.1016/j.msea.2014.11.036

[23] Li, X., Zhou, Q., Zhao, S., Chen, J.: Procedia Engineer., 81, 2014, p. 1799. doi:10.1016/j.proeng.2014.10.235

[24] Hsu, H. C., Wu, S. C., Hong, Y. S., Ho, W. F.: J Alloy Compd., 479, 2009, p. 390. doi:10.1016/j.jallcom.2008.12.064

[25] Wang, J. L., Liu, L. B., Tuo, B. Y., Bai, W. M., Wang, X., Li, X., Hu, X. P.: J Phase Equil. Diff., 36, 2015, p. 248. doi:10.1007/s11669-015-0377-3

[26] Miura, K., Yamada, N., Hanada, S., Jung, T. K., Itoi, E.: Acta Biomaterialia, 7, 2011, p. 2320. doi:10.1016/j.actbio.2011.02.008

[27] Nouri, A., Chen, X. B., Li, Y. C., Yamada, Y. S. Hodgson, P. D., Wen, C. E.: Mat Sci Eng A-Struct., 485, 2008, p. 562. doi:10.1016/j.msea.2007.10.010

[28] Kohn, D. H., Ducheyne, P.: J Mater Sci., 26, 1991, p. 328. doi:10.1007/BF00576523

[29] Niinomi, M., Kobayashi, T.: ISIJ International, 31, 1991, p. 848. doi:10.2355/isijinternational.31.848
[30] Ye, X. X., Chen, B., Shen, J. H., Umeda, J., Kondoh, K.: J Alloy Compd., 709, 2017, p. 381. doi:10.1016/j.jallcom.2017.03.171

[31] Cao, Y. K., Zeng, F. P., Liu, B., Liu, Y., Lu, J. Z., Gan, Z. Y., Tang, H. P.: Mat. Sci. Eng. A-Struct., 654, 2016, p. 418. doi:10.1016/j.msea.2015.12.058

[32] Zhang, L. C., Attar, H.: Adv. Eng. Mater., 18, 2016, p. 463. doi:10.1002/adem.201500419

[33] Abkowitz, S., Rowell, D.: JOM, 38, 1986, p. 36. doi: $10.1007 / \mathrm{BF} 03257786$

[34] Henriques, V. A. R., Galvani, E.T., Petroni, S. L. G., Paula, M. S. M., Lemos, T. G.: J. Mater. Sci., 45, 2010, p. 5844. doi:10.1007/s10853-010-4660-8

[35] Whittaker, P.: Powder Metallurgy Review, 2014. http://www.pm-review.com/dynamet-technologyapproved-by-boeing-as-qualified-supplier-for-powdermetallurgy-titanium-alloy-products/

[36] Zhang, F., Reich, M., Kessler, O., Burkel, E.: Mater. Today, 16, 2013, p. 192. doi:10.1016/j.mattod.2013.05.005

[37] Eriksson, M., Radwan, M., Shen, Z.: Int. J Refract Met. Hard Mater., 36, 2013, p. 31. doi:10.1016/j.ijrmhm.2012.03.007

[38] Sun, Y., Haley, J., Kulkarni, K., Aindow, M., Lavernia, E. J.: J Alloy Compd., 648, 2015, p. 1097. doi:10.1016/j.jallcom.2015.07.079

[39] Li, S. F., Sun, B., Imai, H., Kondoh, K.: Carbon, 61, 2013, p. 216. doi:10.1016/j.carbon.2013.04.088

[40] Dudek, A., Klimas, M.: Materialwissenschaft und Werkstofftechnik, 46, 2015, p. 237. doi:10.1002/mawe.201500334

[41] Weiss, B., Stickler, R., Sychra, H.: Metal Powder Report, 45, 1990, p. 187. doi:10.1016/S0026-0657(10)80087-6

[42] Hadrboletz, A., Weiss, B.: Int. Mater. Rev., 42, 1997, p. 1. doi:10.1179/imr.1997.42.1.1

[43] Zhang, D. C., Yang, S., Wei, M., Mao, Y. F., Tan, C. G., Lin, J. G.: J Mech. Behav. Biomed. Mater., 13, 2012, p. 156. doi:10.1016/j.jmbbm.2012.04.017

[44] Henriques, V. A. R., de Campos, P. P., Cairo, C. A. A., Bressiani, J. C..: Mater. Res., 8, 2005, p. 443. doi:10.1590/S1516-14392005000400015

[45] Bolzoni, L., Ruiz-Navas, E. M., Gordo, E.: Mater. Charact., 84, 2013, p. 48. doi:10.1016/j.matchar.2013.07.009 